\title{
UMA ESTRATÉGIA DIDÁTICA PARA DISCUSSÃO DA CONCEPÇÃO DE CIÊNCIA E DO CIENTISTA COM ALUNOS DO ENSINO FUNDAMENTAL
}

\author{
A DIDACTIC STRATEGY FOR DISCUSSION OF SCIENCE AND SCIENTIST \\ CONCEPTION WITH ELEMENTARY EDUCATION STUDENTS
}

\author{
Boniek Venceslau da Cruz Silva \\ Universidade Federal do Piauí / Centro de Ciências da Natureza / boniek@ufpi.edu.brl
}

Fernanda Maria de Sousa Calaça

Universidade Federal do Piauí / Centro de Ciências da Natureza / f-gabriel27@hotmail.com

\section{Resumo}

O ensino da Natureza da Ciência ( $\mathrm{NdC}$ ) tem sido defendido como um dos caminhos para a construção de um cidadão alfabetizado cientificamente. Várias pesquisas retratam o papel da $\mathrm{NdC}$ na construção de currículos de ciência, com destaque ao contexto brasileiro. Contudo, as mesmas pesquisas também relatam a presença de concepções inadequadas da $\mathrm{NdC}$ em estudantes de todos os níveis de ensino. Este fato chama a atenção para a necessidade da elaboração de propostas didática que visem problematizá-las, buscando o ensino mais adequado de conteúdos sobre a NdC. Neste trabalho buscamos justamente acessar a concepção de Ciência e da imagem do cientista de um grupo de estudantes do ensino fundamental, de uma escola pública, de Teresina- Piauí, com o intuito de construir uma sequência didática para problematização de possíveis concepções inadequadas. Os principais resultados da pesquisa apontam que (a) as concepções de Ciência e da imagem de cientista do grupo se aproximam das ditas inadequadas pela literatura e (b) a utilização de atividades lúdicas, reflexivas e interativas como, por exemplo, o jogo didático e o uso de vídeos potencializam o ensino de conteúdos sobre a NdC.

Palavras-chave: Ensino de Ciências; Natureza da Ciência; Concepção de Ciência; Cientista; Estratégia Didática.

\section{Abstract}

The teaching of the Nature of Science (NOS) is used as one of the ways for scientific literacy in citizens. Researches show the NOS role in the construction of science curricula, with emphasis on the Brazilian context. However, the same researchers also report the presence of inadequate conceptions of NOS in students of all levels of education. This fact points to the need for the elaboration of didactic proposals to problematize them, seeking the most appropriate educational content on the NOS. In this work, we investigate the conception of 
Science and Scientist image of a group of elementary school students in a public school, at the city of Teresina, state of Piaui, with object to build a didactic sequence for questioning for possible misconceptions. The results of the research show that (a) the conceptions of Science and the image of group scientist are similar with the literature and (b) the use of fun, reflexive and interactive activities, for example, didactic game and videos enhances the teaching of content about NOS

Keywords: Science Education; Nature of Science; Conception of Science; Scientist; Didactic Strategy.

\section{Introdução}

Nas últimas décadas, com a consolidação da Didática das Ciências como uma área de pesquisa de corpo robusto e coeso, tanto pesquisadores como professores de ciências vêm presenciando uma revolução no seu campo de trabalho, marcada por uma profunda proliferação de ideias, propostas e materiais inovadores, que visam a estruturar melhorias nos diferentes níveis de ensino (ADÚRIZ-BRAVO, 2005).

Dentre as várias linhas de pesquisa emergentes dessa nova área de pesquisa (por exemplo: resolução de problemas e concepções alternativas), existem algumas que têm por objetivo discutir relações relativas à natureza do conhecimento científico e suas implicações no ensino-aprendizagem das ciências.

De certa forma, como aponta Adúriz-Bravo (2005), pode-se inserir nesse campo a história e a sociologia da ciência no ensino. Essas novas áreas realizam estudos sobre a ciência, guiando-se por aportes os mais diversos possíveis, gerando estudos de diferentes aspectos da atividade científica, tais quais: como o conhecimento científico se transforma com o passar do tempo, os valores levados em conta pelas comunidades científicas na hora da formulação de uma teoria, a relação entre a ciência e a sociedade, a falibilidade do cientista, o entendimento da imagem do cientista pela sociedade, dentre outras.

Para Adúriz-Bravo (2005), o interesse pelo estudo desse campo advém da relação entre os fatos citados e o ensino de ciências. Isso proporciona, dentre outras coisas, uma reflexão sobre o que é o conhecimento científico, uma ajuda à superação de obstáculos na aprendizagem dos alunos, um favorecimento à elaboração de novas práticas e materiais para o ensino e, por fim, um auxílio à prática da contestação de algumas certezas sobre a ciência, sua metodologia e seus objetivos.

Todas estas preocupações desembocam nas relações entre a Natureza da Ciência $(\mathrm{NdC})$ e seu ensino. Contudo, uma explicação consensual sobre o que seria $\mathrm{NdC}$ não é trivial, pois remete a profundas discussões de cunho epistemológico, principalmente. Não temos a pretensão de adentrar nela neste artigo, mas sinalizaremos um breve ponto de vista sobre suas relações com o ensino, pois elas fundamentam este trabalho. 
Convergimos com Moura (2008), o qual entende a NdC como um conjunto de conhecimentos sobre a ciência que trata de seus limites, das influências com a sociedade da época, dos seus objetivos, das metodologias, da aceitação ou rejeição de ideias científicas, dos erros cometidos pelos cientistas ao tentar formular uma lei ou teoria e de outros tópicos.

Nossas preocupações vão ao encontro das discussões elaboradas por Lederman (1992; 2007), McComas e Olson (2002), Acevedo et al (2005) e Martins (2015), os quais demonstram uma preocupação diante das concepções sobre o cientista apresentadas por professores e estudantes dos diferente níveis de ensino como, por exemplo, a imagem caricatura do cientista (homem, velho, desleixado) e do seu trabalho (exclusivamente no laboratório, vestido de jaleco branco e rodeado de vidrarias).

No que diz respeito à concepção de Ciência de professores e estudantes de diferente níveis de ensino, Silva (2010) e Santos e Silva (2013), em estudos com estudantes da educação básica e com futuros professores de Ciências, mostram que ambos os grupos apresentam uma concepção de Ciência relacionada a sua natureza empírica e indutiva.

Os pesquisadores ainda retratam a natureza do experimento como critério exclusivo de demarcação do que é ou não Ciência. Por fim, sobre a imagem do cientista, os seus estudos convergem os demais apresentados, ou seja, uma imagem do cientista idoso, preso no laboratório, elaborador de experimentos inexplicáveis e antissociais.

Já, sobre o ensino de conteúdos relacionados à natureza do conhecimento científico, notadamente no ensino fundamental, encontramos na literatura especializada algumas divergências sobre a potencialidade de discussões neste sentido.

Por exemplo, Carvalho (2001) e Lederman (2007) relatam possíveis dificuldades no ensino de conteúdos relacionados à natureza do conhecimento científico, como, por exemplo, formação inadequada dos professores de Ciências e dificuldade de abordagem de tais conceitos sobre a NdC.

Contudo, Santos et al (2017), em um trabalho de construção, aplicação e problematização de uma sequência didática, apresentam resultados satisfatórios relacionados à discussão de conteúdos sobre a Ciência no ensino fundamental, com destaque ao papel da mulher na Ciência.

Portanto, partindo dos pressupostos de Lederman (1992; 2007), Silva (2010) e Santos e Silva (2013), os quais, em diferentes localidades e para públicos semelhantes encontram concepções relacionadas à Ciência e ao cientista equivalentes e, especialmente, amparados no trabalho de Santos et al (2007), no qual é discutido a potencialidade de abordagem de conteúdos sobre à natureza do conhecimento no ensino fundamental, propomos uma estratégia didática para discussão e problematização de concepções de estudantes do ensino fundamental relacionadas ao termo Ciência e a imagem do cientista.

Desenho do estudo: objetivos, participantes, instrumentos de coleta de dados e processo de aplicação das ferramentas didáticas 
A pesquisa se configura como de natureza qualitativa, pois segundo Marconi (2003) é característico, neste tipo de estudo: preocupação com o processo desenvolvido, e não simplesmente com o produto final; contato direto do pesquisador com o local que está sendo investigado; os dados coletados são, quase exclusivamente, descritivos: gravações, entrevistas, entre outros e, por fim, a variedade de pontos de vista.

Configura-se, também, como de natureza interpretativa, pois, conforme descreve Moreira (2011), o foco deste tipo de pesquisa se encontra na interpretação dos significados atribuídos pelos participantes da pesquisa. Nela, o pesquisador fica imerso no fenômeno de interesse.

$\mathrm{Na}$ nossa investigação, devido à natureza da investigação, utilizamos variados instrumentos de coleta de dados, conforme serão descritos a seguir. A análise dos dados assumiu uma natureza descritiva e interpretativa, na qual a organização do material culminou na diimagem de categorias e na posterior procura de relações entre essas categorias.

Entendemos que a análise de dados qualitativos é o ponto fulcral da pesquisa qualitativa em geral. Neste sentido, utilizamos como referencial Bardin (2009). Buscamos a identificação, seleção, classificação e categorização dos dados disponibilizados de maneira descritiva e interpretativa nos questionários.

A estratégia didática foi vivenciada por 45 alunos, do $8^{\circ}$ e $9^{\circ}$ anos, pertencentes a uma escola da rede pública estadual, na zona urbana, da cidade de Teresina-Piauí. Ela foi dividida em três etapas, a saber: (1) questionário inicial, com o intuito de mapear 0 conhecimento inicial sobre a ciência e a imagem do cientista dos estudantes; (2) jogo didático, o qual problematizou as concepções iniciais dos alunos coletadas no questionário inicial e (3) um filme sobre a criação da carga elétrica, o qual abordava o dia-a-dia de um cientista.

O ponto de partida da nossa estratégia didática, conforme exposto acima, foi a aplicação de um questionário inicial. Ele continha quatro partes: (a) associação livre de palavras relacionada a palavra ciência; (b) três questões abertas, com o intuito de mapear as concepções sobre o entendimento da ciência e a imagem do cientista; (c) um desenho sobre a imagem dos cientistas em seu ambiente de trabalho e (d) repertório das características sociais, físicas e psicológicas dos cientistas. Nos quadros 1 e 2, apresentamos o questionário na íntegra.

Quadro 1: Questionário e seus objetivos

\begin{tabular}{|c|c|}
\hline Questões & Objetivos \\
\hline $\begin{array}{l}\text { 1- Escrevam cinco palavras que lembram } \\
\text { termo ciência. }\end{array}$ & $\begin{array}{l}\text { Mapear palavras que remetem o } \\
\text { termo Ciências pelos participantes da } \\
\text { investigação. }\end{array}$ \\
\hline
\end{tabular}


2- Respondam as questões abaixo;

a) O que é ciência?

b) Para que serve a Ciência?

c) Para você, qual é a função do cientista na sociedade?

3- Faça um desenho mostrando o cientista no seu local de trabalho.

Fonte: Arquivo pessoal dos autores

Quadro 2: Repertório das características sociais, físicas e psicológicas dos cientistas

\begin{tabular}{|l|l|}
\hline Sexo & \\
\hline Idade & \\
\hline Roupas usadas & \\
\hline Convívio social & \\
\hline Características Psicológicas & \\
\hline Ambiente de trabalho & \\
\hline Instrumentos de trabalho & \\
\hline Local de Trabalho & \\
\hline
\end{tabular}

Fonte: Arquivo pessoal dos autores

Diferente das partes do questionário, contidas no quadro 1 , o repertório das características sociais, físicas e psicológicas dos cientistas, apresentado no quadro 2, foi aplicado no final da estratégia didática. Procuramos, com isso, possíveis mudanças no entendimento da imagem do cientista dos participantes da investigação.

Após o mapeamento das concepções dos participantes sobre a Ciência e a imagem do cientista, buscamos problematiza-la com o uso de um jogo didático e de um vídeo. A partir de agora, discutiremos a fase de construção de ambas as ferramentas didáticas, iniciando pelo jogo didático.

$\mathrm{Na}$ nossa estratégia didática, ele foi definido como uma atividade com o intuito de problematizar a concepção de ciência e da imagem cientista dos participantes. Para a sua elaboração foram consultados livros didáticos de ciências do ensino fundamental (veja, por exemplo: Godoy; Ogo; 2012; Gowdak; Martins, 2012; Barros; Paulino, 2013) e artigos referentes ao tema NdC (Silva, 2010; Santos; Silva, 2013).

O jogo "Vamos conhecer a Ciência" buscou estimular a aprendizagem dos alunos de aspectos da NdC, como, por exemplo, a concepção de Ciência e imagem do cientista e do seu local de trabalho. Buscamos a elaboração de atividades mais lúdicas e interativas. 
A ideia do jogo era problematizar possíveis concepções inadequadas nos estudantes acerca dos temas apresentados acima. Utilizamos este pressuposto como guia, pois conforme sinaliza a literatura especializada (veja, por exemplo: Lederman (1992; 2007); Silva (2010) e Silva e Santos (2013)), o público, com o qual trabalhávamos, possivelmente apresentariam estas concepções, pois, como discutem Lederman (2007) e Silva (2010), elas são atemporais e não variam, significativamente, de local para local.

O jogo didático, propriamente dito, é composto por duas caixas. Elas foram confeccionadas com isopor e cobertas com cartolina e identificadas pelas cores amarela, para o termo Ciência e, branca, para o termo cientistas, conforme apresentamos na figura 1a. As quinze questões jogo (sete sobre o termo Ciência e oito para o termo cientista) foram confeccionadas também com papel de cartolinas amarela e branca (figura 1b).

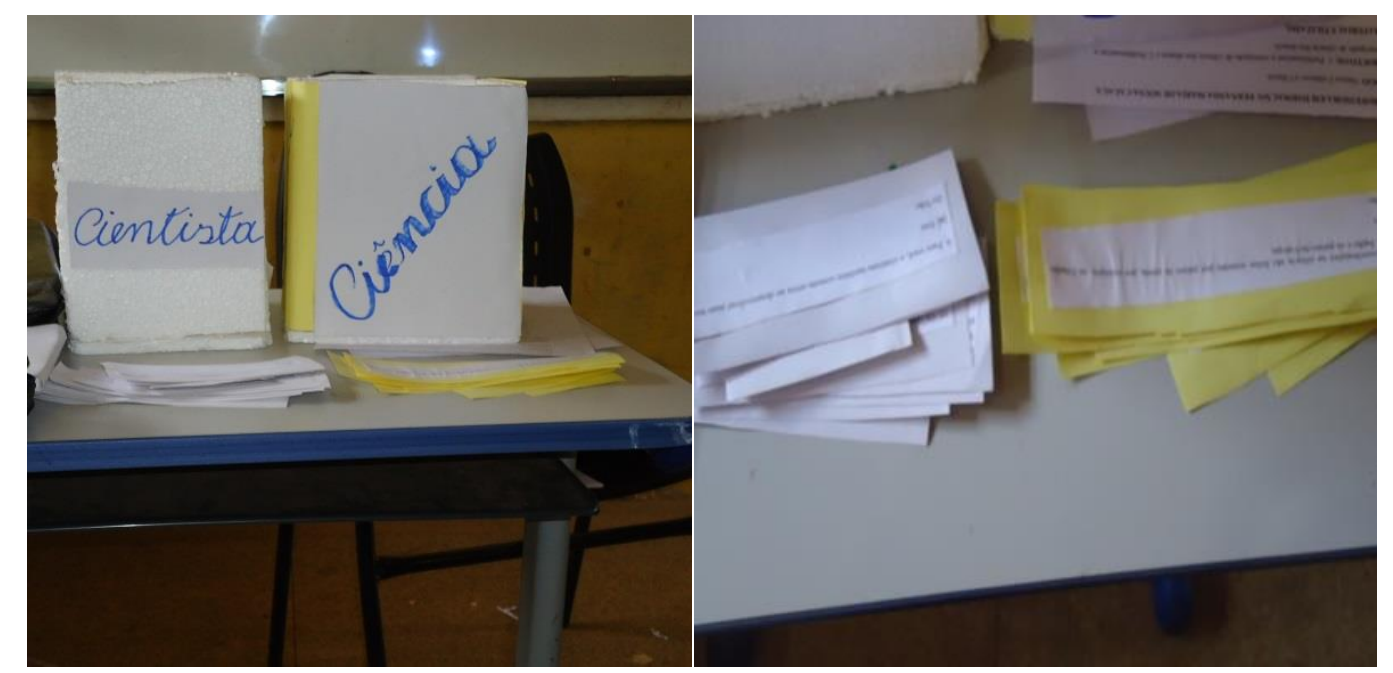

Figura 1a e 1b - Caixas dos termos Ciência e cientista e questões do jogo

Fonte: Arquivo pessoal dos autores

O jogo didático apresentava 5 etapas, descritas no quadro 3, abaixo.

Quadro 3: Etapas do jogo didático

\begin{tabular}{|c|l|}
\hline Etapas & \multicolumn{1}{|c|}{ Descrição } \\
\hline 1 & $\begin{array}{l}\text { Os grupos foram organizados em duas filas. O coordenador da atividade } \\
\text { (professor) organizou as caixas no centro das filas. Cada grupo elegeu um } \\
\text { capitão para representá-los. Os demais alunos ficaram responsáveis por } \\
\text { assessorar o seu capitão nas respostas. }\end{array}$ \\
\hline 2 & $\begin{array}{l}\text { O grupo que iniciou a partida foi escolhido por uma disputa de par ou ímpar dos } \\
\text { seus capitães. Após a disputa, o jogo começou e o capitão da equipe escolheu } \\
\text { entre as duas caixas e tirou uma questão. }\end{array}$ \\
\hline 3 & $\begin{array}{l}\text { Cada grupo teve dois minutos para responder as questões. O tempo foi } \\
\text { controlado pelo coordenador da atividade. Ele avisava o tempo decorrido aos } \\
\text { participantes, avisando-lhes quando faltava 1 minuto e 30 segundos do tempo } \\
\text { para as respostas. }\end{array}$ \\
\hline 4 & Depois de passado o tempo determinado, a questão passava para o outro grupo. \\
\hline
\end{tabular}


cientistas.

3) Os cientistas ao desenvolverem suas atividades, eles...

...trabalham de forma isolada nos seus laboratórios.

...trabalham com outros cientistas, trocando informações.

Fonte: Arquivo pessoal dos autores

Para encerrar a estratégia didática, utilizamos um questionário final. Buscamos analisar o jogo didático, o qual foi a principal ferramenta didática da nossa estratégia didática. Ele é apresentado no quadro 5.

Quadro 5: Questionário avaliativo do jogo "Vamos conhecer a Ciência"

1) Para você, qual a importância dos jogos didáticos para o ensino de ciências?

( ) Ruim ( ) Péssimo ( ) Regular ( ) Bom ( ) Ótimo

2) O que você achou do jogo Vamos conhecer a Ciência? Ela ajuda para estudar os conteúdos sobre Ciência?
( ) Ruim
( ) Péssimo
( ) Regular
( ) Bom
( ) Ótimo

3) Sobre o tempo do jogo. Você achou adequada sua aplicação na aula (aproximadamente 50 minutos)? Em caso de resposta negativa, justifique sua resposta.

Fonte: Arquivo pessoal dos autores.

No próximo tópico, apresentamos um olhar sobre a estratégia didática, apresentando os resultados de sua aplicação.

Discutindo os resultados: um olhar sobre a estratégia didática utilizada para a discussão de concepções sobre a Ciência e a imagem do cientista

Iniciaremos a nossa discussão pelo questionário inicial, o qual foi dividido em três etapas. A primeira apresentada os resultados da livre associação de palavras relacionadas ao termo "Ciência". Nela, os 48 participantes citaram 59 palavras diferentes. O quadro 6 apresenta as palavras que mais receberam menções.

Quadro 6: Menções ao termo "Ciência"

\begin{tabular}{|c|c|c|}
\hline Ordem & Palavras & Menções \\
\hline 1 & Corpo Humano & 21 \\
\hline 2 & Animais & 10 \\
\hline 3 & Reprodução humana & 08 \\
\hline 4 & Células & 07 \\
\hline 5 & Natureza & 06 \\
\hline 6 & Descobertas & 04 \\
\hline 7 & Sentidos & 03 \\
\hline
\end{tabular}

Fonte: Arquivo pessoal dos autores 
As menções ao termo Ciência vão ao encontro dos resultados encontrados em Silva (2010), o qual também relatou que os alunos da educação básica, basicamente, remetem o termo Ciência aos conceitos e conteúdos relacionados à Biologia.

Conforme discute Silva (2010), geralmente, as aulas de Ciências Naturais, no ensino fundamental, são ministradas por biólogos, os quais, às vezes, renegam os conteúdos de Física e Química, em alguns casos, devido ao pouco conhecimento dos mesmos. Este fato pode remeter aos resultados que apresentamos no quadro 5 , ou seja, uma relação, quase direta, entre Ciências Naturais às Ciências Biológicas.

$\mathrm{Na}$ segunda parte do questionário, os participantes responderam as questões apresentadas no quadro 1. Abaixo, com o auxílio das tabelas 1, 2 e 3, apresentamos os principais resultados descritos a partir da sua análise de conteúdo.

Tabela 1: O que é Ciência?

\begin{tabular}{|l|c|c|}
\hline \multicolumn{1}{|c|}{ Categorias } & $\begin{array}{c}\mathbf{N}^{\circ} \text { de } \\
\text { alunos }\end{array}$ & Frequência (\%) \\
\hline Estudo dos seres vivos e o meio ambiente & 24 & 50 \\
\hline Estudo das doenças dos seres vivos & 12 & 25 \\
\hline Estudo do corpo humano & 12 & 25 \\
\hline Total & 48 & 100 \\
\hline
\end{tabular}

Fonte: Arquivo dos autores

Notamos, nesta parte do questionário, uma retomada ao que foi notado na associação de palavras, ou seja, a concepção de Ciência atrelada diretamente às Ciências Biológicas, conforme destacado, também, em pesquisas anteriores por Silva (2010) e Santos et al (2017).

A tabela 2 apresenta a finalidade da Ciência, a partir da compreensão dos participantes da pesquisa.

Tabela 2: Para que serve a Ciência?

\begin{tabular}{|l|c|c|}
\hline \multicolumn{1}{|c|}{ Categorias } & $\begin{array}{c}\mathbf{N}^{\circ} \text { de } \\
\text { alunos }\end{array}$ & Frequência (\%) \\
\hline Descobrir coisas novas & 24 & 50 \\
\hline Realizar pesquisas & 18 & 37,5 \\
\hline Ensinar a ciência & 6 & 12,5 \\
\hline Total & 48 & 100 \\
\hline
\end{tabular}

Fonte: Arquivo dos autores

A tabela 3 sistematiza o entendimento dos participantes sobre a função dos cientistas na sociedade. 
Tabela 3: Função social do cientista

\begin{tabular}{|l|c|c|}
\hline \multicolumn{1}{|c|}{ Categorias } & $\mathbf{N}^{\circ}$ de alunos & Frequência (\%) \\
\hline Fazer novas descobertas & 36 & 75 \\
\hline Realizar pesquisa & 6 & 12,5 \\
\hline $\begin{array}{l}\text { Trazer o que ele aprendeu para o } \\
\text { mundo }\end{array}$ & 6 & 12,5 \\
\hline Total & 48 & 100 \\
\hline
\end{tabular}

Fonte: Arquivo dos autores

Por fim, a terceira parte do questionário inicial teve como objetivo acessar a imagem do cientista a partir de desenhos feitos pelos participantes. Os desenhos, que representaram o ambiente de trabalho dos cientistas, na sua totalidade, resumiram-se aos expostos abaixo. Neles, os participantes representavam cientistas "homens" em laboratórios realizando experimentos e repleto de vidrarias.

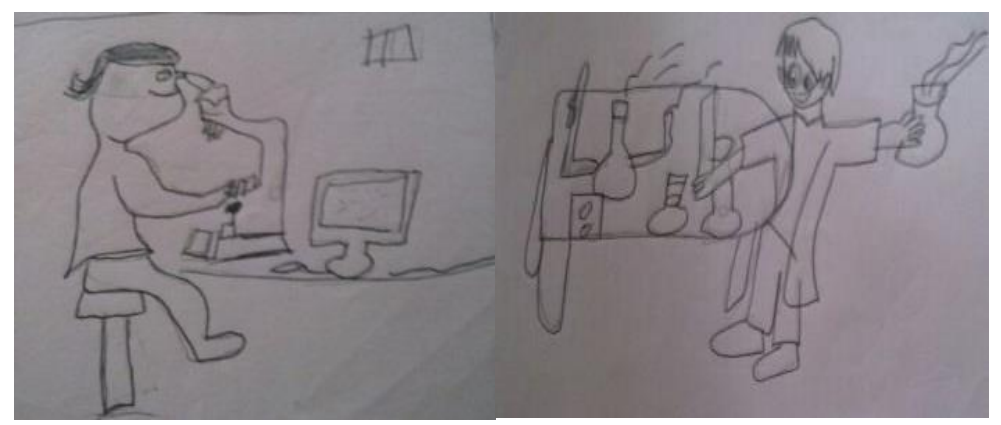

Figura 2 - Cientista no local de trabalho

Fonte: Arquivo pessoal dos autores

A última parte do questionário inicial foi aplicado no final da estratégia didática. Buscamos caracterizar possíveis mudanças na imagem do cientista, a partir da interpretação do repertório social, físico e psicológico. Os resultados podem ser observados no quadro 7 .

Quadro 7: Repertório social, físico e psicológico dos cientistas

\begin{tabular}{|c|c|c|}
\hline Atributos & Caraterísticas & Citações \\
\hline \multirow{2}{*}{ Sexo } & Masculino e feminino & 15 \\
\hline \multirow{3}{*}{ Idade } & Homem & 05 \\
\cline { 2 - 3 } & Mulher & 04 \\
\cline { 2 - 3 } & Velho & 01 \\
\cline { 2 - 3 } & 30 a 60 anos & 16 \\
\hline \multirow{2}{*}{ Roupas usadas } & Jalecos, roupas branco. & 15 \\
\cline { 2 - 3 } & Calça, luva, touca, bata, óculos. & 06 \\
\cline { 2 - 3 } & Roupas do dia-a-dia & 03 \\
\hline Convívio social & Normal & 06 \\
\hline Características psicológicas & Equilibrado e normal & 15 \\
\hline
\end{tabular}




\begin{tabular}{|c|c|c|}
\hline & Inteligente e bacana & 01 \\
\hline \multirow{3}{*}{ Ambiente de trabalho } & Lugares fechados & 01 \\
\cline { 2 - 3 } & Laboratório & 04 \\
\cline { 2 - 3 } & Clínica & 01 \\
\cline { 2 - 3 } & Floresta & 01 \\
\hline Instrumentos de trabalho & Microscópio & 05 \\
\cline { 2 - 3 } & Laboratório & 02 \\
\cline { 2 - 3 } & Lupa & 02 \\
\cline { 2 - 3 } & Computador & 02 \\
\hline \multirow{2}{*}{ Local de Trabalho } & Salas fechadas & 07 \\
\cline { 2 - 3 } & Laboratório & 03 \\
\cline { 2 - 3 } & Prédio & 01 \\
\hline
\end{tabular}

Fonte: Arquivo pessoal dos autores

\section{A análise do jogo didático "Vamos conhecer a Ciência"}

O jogo didático teve como objetivo problematizar as concepções de Ciência e a imagem do cientista e do seu local de trabalho. Abaixo, apresentamos algumas imagens da sua aplicação.

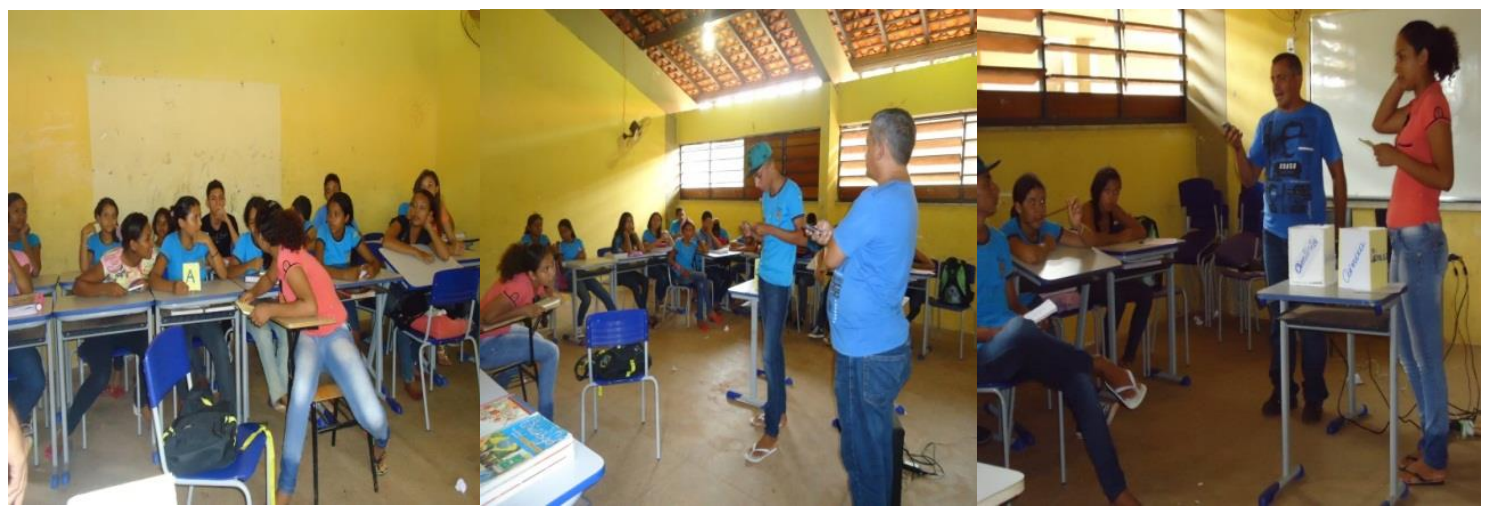

Figura 3a, 3b e 3c - Aplicação do jogo "Vamos conhecer a Ciência"

Fonte: Arquivo pessoal dos autores

No geral, o jogo didático foi bem recebido pelos participantes, sendo avaliado como ótimo nos quesitos potencialidades para o ensino de Ciências e tempo de aplicação.

\section{A utilização do vídeo}

Foram utilizados dois questionários conjuntamente com o vídeo, conforme exposto anteriormente. Notamos uma variação nas concepções dos participantes após o preenchimento dos questionários pré e pós-vídeos. O quadro 8 resume os resultados desta etapa. 
Quadro 8: Concepções sobre o cientista antes do vídeo

\begin{tabular}{|c|c|c|}
\hline $\begin{array}{c}\text { Questão 1: Quando os } \\
\text { cientistas estão trabalhando, } \\
\text { você acredita que ... }\end{array}$ & $\begin{array}{c}\text { Questão 2: Nas atividades } \\
\text { dos cientistas, você acredita } \\
\text { que outros fatores interferem } \\
\text { no seu trabalho, como } \\
\text { pressão da sociedade, dos } \\
\text { políticos, da religião, entre } \\
\text { outros ... }\end{array}$ & $\begin{array}{c}\text { Questão 3: Os cientistas, ao } \\
\text { desenvolverem suas } \\
\text { atividades, eles }\end{array}$ \\
\hline $\begin{array}{c}70 \% \text { concordam entre si } \\
30 \% \text { discordam entre si }\end{array}$ & $\begin{array}{c}90 \% \text { não interferem } \\
10 \% \text { interferem }\end{array}$ & $\begin{array}{c}80 \% \text { trabalham de forma } \\
\text { isolada }\end{array}$ \\
& $20 \%$ trabalham em conjunto \\
\hline
\end{tabular}

Fonte: Arquivo pessoal dos autores

O quadro 9 sintetiza o entendimento dos estudantes após a visualização do vídeo.

Quadro 9: Concepções sobre o cientista depois do vídeo

\begin{tabular}{|c|c|c|}
\hline $\begin{array}{c}\text { Questão 1: Por que você } \\
\text { acha que durante o processo } \\
\text { de descoberta da energia } \\
\text { elétrica, os cientistas não } \\
\text { acreditavam nas ideias de } \\
\text { Thomas Edison, chegando a } \\
\text { brigarem entre si? Você acha } \\
\text { que a rivalidade entre } \\
\text { cientistas é positiva para a } \\
\text { ciência? Explique. }\end{array}$ & $\begin{array}{c}\text { Questão 2: Depois do vídeo } \\
\text { assistido, como você acha } \\
\text { que a ciência é feita e se } \\
\text { desenvolve? }\end{array}$ & $\begin{array}{c}\text { Questão 3: Que fatores você } \\
\text { acha que foram decisivos } \\
\text { para que a equipe de } \\
\text { Thomas Edison fosse bem- } \\
\text { sucedida na descoberta da } \\
\text { energia elétrica? }\end{array}$ \\
\hline $\begin{array}{l}100 \% \text { dos participantes } \\
\text { destacaram a rivalidade } \\
\text { entre os cientistas como um } \\
\text { fator preponderante para o } \\
\text { desenvolvimento } \\
\text { eletricidade }\end{array}$ & $\begin{array}{lr}100 \% \text { dos } & \text { participantes } \\
\text { destacaram } & \text { como } \\
\text { características } & \text { do } \\
\text { desenvolvimento da Ciência: } \\
\text { conhecimento, força de } \\
\text { vontade, união, inteligência e } \\
\text { estudos. }\end{array}$ & $\begin{array}{l}100 \% \text { dos participantes } \\
\text { destacaram como fatores } \\
\text { decisivos para a descoberta } \\
\text { da eletricidade: persistência, } \\
\text { inteligência, aprender com os } \\
\text { erros, pesquisa e tentativas. }\end{array}$ \\
\hline \multicolumn{3}{|c|}{ Fala dos participantes } \\
\hline $\begin{array}{l}\text { A1: "Sim. Porque os cientistas não } \\
\text { estavam, mas acreditando na } \\
\text { capacidade de Thomas Edison.". } \\
\text { A23: "Sim. Porque muita às vezes } \\
\text { eles precisam dessa rivalidade } \\
\text { para concordaram em uma só } \\
\text { ideia.". } \\
\text { A33: "SIM. Porque se não eles não } \\
\text { conseguem o que para realizar } \\
\text { uma pesquisa". }\end{array}$ & $\begin{array}{l}\text { A11: "Acho que se desenvolve } \\
\text { com esforço e inteligência dos } \\
\text { cientistas". } \\
\text { A13: "Se desenvolve pela união } \\
\text { das pessoas e nos estudos feitos } \\
\text { por elas". }\end{array}$ & $\begin{array}{l}\text { A31: "Acho que aprender com } \\
\text { seus erros foi fundamental" } \\
\text { A13: "Ele foi muito persistente e } \\
\text { não desistiu com seus erros." } \\
\text { A43: "As tentativas, erros e } \\
\text { persistência de Thomas Edison faz } \\
\text { ele ser vencedor". }\end{array}$ \\
\hline
\end{tabular}

Fonte: Arquivo pessoal dos autores

No próximo trabalho, apresentamos nossas considerações finais. 


\section{Considerações Finais}

O estudo desenvolvido aponta para uma tentativa de discussão da concepção de Ciência e da imagem dos cientistas com alunos do ensino fundamental, de uma escola pública, no Brasil. Um dos resultados encontrados é que as concepções iniciais de Ciência e da imagem do cientista do grupo investigado se aproximam das já discutidas e problematizadas na literatura especializada.

Este fato valida e justifica a nossa pretensão de elaboração e aplicação de estratégias didáticas, que visam problematizar estas compreensões de Ciência com estudantes do ensino fundamental, mesmo com as aparentes impossibilidades descritas na literatura especializada e neste trabalho.

$\mathrm{Na}$ elaboração dos instrumentos de coleta de dados e das ferramentas didáticas, tivemos a preocupação de elaborar possibilidades tanto de acessar as concepções da $\mathrm{NdC}$, que idealizamos investigar, como problematizá-las, buscando um ensino mais adequado como, por exemplo, da imagem do cientista e do seu local de trabalho.

$\mathrm{Na}$ pesquisa, compreendemos que a construção da sequência didática, baseadas em atividades mais lúdicas e interativas, favoreceu na problematização de tais concepções da NdC. Dessa forma, o uso do jogo didático e de vídeos possibilitaram um ensino mais qualificado de aspectos da NdC, conforme, também, destacado, por exemplo, em Santos (2017), em estudos anteriores.

No que diz respeito às estratégias didáticas, no geral, elas foram bem aceitas pelos alunos. Compreendemos que, a partir delas, os alunos puderam perceber características e funcionalidades do cientista escondidas, às vezes, dentro de livros didáticos, como, por exemplo, o papel da mulher na ciência, outros locais de trabalhos dos pesquisadores, a relevância de fatores extracientíficos (religião, política, economia) e a falibidade dos cientistas.

Por fim, a construção de sequências didáticas mais lúdicas e interativas possibilitou a reflexiva e um melhor entendimento de tais concepções. Portanto, talvez este seja um caminho para alcançarmos melhores resultados no ensino-aprendizagem de conteúdos sobre a Ciência.

\section{Agradecimentos}

Agradecemos aos árbitros da revista pela minuciosa análise deste trabalho e suas valiosas sugestões que contribuíram sobremaneira para a melhoria do mesmo. 


\section{Referências}

ACEVEdo, J. A.; VÁZQUeZ, Á.; MARTín, M.; OlIVA, J. M.; ACEVEdo, P., PAIXÃO, F.; MANASSERO, M. A. Natureleza de la ciencia y educación científica para la participación ciudadana. Una revisión crítica. Revista Eureka sobre Enseñanza y Divulgación de las Ciencias. v. 2, n. 2, p 121-140, 2005.

ADÚRIZ-BRAVO, A. Uma introducción a la natureza de la ciencia: La epistemologia en la enseñanza de las ciências naturales. 1르ed. Buenos Aires: Fondo de Cultura Econômica, 104p, 2005.

BARDIN, L. Análise de conteúdo. Lisboa: Edições 70, 2009.

BARROS, C.; PAULINO, W. Ciências: o meio ambiente. São Paulo: Editora Ática, 2013.

CARVALHO, L. M. A natureza da ciência e o ensino das ciências naturais: tendências e perspectivas na formação de professores. Pro-posições, v. 12, n. 1, p. 139-150, 2001.

GODOY, L.; OGO. M. Vontade de saber ciências - volume 6. São Paulo: Editora FTD, 2012

GOWDAK, D.; MARTINS, E. Ciências novo pensar: meio ambiente. São Paulo: Editora FTD, 2012.

LEDERMAN, N. G. Students' and teachers' conceptions of the nature of science: A review of the research. Journal of Research in Science Teaching, v. 29, n. 4, p. 331-359, 1992.

. Nature of Science: past, present and future. In: Abell, S.K (Org); Lederman, N.G (Org). Handbook of research of Science Education. Mahwal: Lawrence Erlball Associates, p.881-880, 2007.

MARCONI, M. A. Fundamentos de metodologia científica. São Paulo: Atlas, 2003.

MARTINS, A. F. P. Natureza da Ciência no ensino de ciências: uma proposta baseada em "temas" e "questões". Caderno Brasileiro de Ensino de Física, v. 32, n. 3, p. 703-737, 2015.

MOURA, B. A, A aceitação da óptica newtoniana no século XVIII: subsídios para discutir a natureza da ciência no ensino. Dissertação de mestrado, Instituto de Física, Universidade de São Paulo, 2008.

MOREIRA, M.A. Metodologia de Pesquisa em Ensino. São Paulo: Livraria da Física, 2011.

SANTOS, G. D.; SILVA, B. V. C. Natureza da Ciência por alunos de Licenciatura em Física. LatinAmerican Journal of Physics Education, v. 7, p. 630-647, 2013.

SANTOS, M. L.; SILVA, B. V. C.; CARVALHO, H. R.; NASCIMENTO, L. A. Natureza da Ciência no ensino fundamental: Por que não?. Experiências em Ensino de Ciências, v.12, n. 3, p. 1 - 30, 2017.

SILVA, B. V. C . A natureza da ciência pelos alunos do ensino médio: um estudo exploratório. LatinAmerican Journal of Physics Education, v. 4, p. 670-677, 2010.

Submissão: 15/11/2016

Aceite: 05/06/2017 